\title{
Is early discharge safe after naloxone reversal of presumed opioid overdose?
}

\author{
Jeremy Etherington, MD; James Christenson, MD; Grant Innes, MD; Eric Grafstein, MD; \\ Sarah Pennington, RN; John J. Spinelli, PhD; Min Gao, MD, PhD; Brian Lahiffe, BSc; \\ Karen Wanger, MD; Christopher Fernandes, MD
}

\begin{abstract}
Introduction: Patients with suspected opioid overdose frequently require naloxone treatment. Despite recommendations to observe such patients for 4 to 24 hours after naloxone, earlier discharge is becoming more common. This prospective, observational study of patients with presumed opioid overdose examines the safety of early disposition decisions and the accuracy of outcome prediction by physicians 1 hour after the administration of naloxone.

Methods: The study was carried out at St. Paul's Hospital, an inner city teaching centre that cares for most of the injection drug users in Vancouver, BC. Patients were formally assessed 1 hour after receiving naloxone for presumed opioid overdose. Demographics, medical history and physical examination were documented on specific data forms, and physicians recorded their comfort with early discharge. Patients were followed up, and those who required a critical intervention or suffered a pre-defined adverse event (AE) within 24 hours of their 1-hour assessment were identified. Results: Of 573 patients, $48 \%$ were discharged in less than 2 hours, $23 \%$ in $2-4$ hours and $29 \%$ in $>4$ hours. 94 patients who were held in the emergency department (ED) or admitted required a critical intervention, including supplemental oxygen for hypoxia (74), repeat naloxone (52), antibiotics administered intravenously (IV) (14), assisted ventilations (13), fluid bolus for hypotension (12), charcoal for associated life-threatening overdose (6), IV inotropic agents (2), antiarrhythmics for sustained tachycardia $>130$ beats/min (1), and administration of bicarbonate for arterial $\left[\mathrm{HCO}_{3}\right]$ $<5$ or venous $\mathrm{CO}_{2}<5$ (1). Physicians predicted adverse events with $94 \%$ sensitivity and $59 \%$ specificity. No discharged patients suffered a serious AE within 24 hours of ED discharge.

Conclusions: Emergency physicians can clinically identify patients at risk of deterioration after naloxone reversal of suspected opioid overdose. Prolonged observation or hospital admission is not usually required. Selective early discharge of patients with presumed opioid overdose is feasible and appears safe. A clinical prediction rule may be useful in identifying patients eligible for early discharge.
\end{abstract}

\section{RÉSUMÉ}

Introduction : Les patients chez qui l'on soupçonne une intoxication aux opiacés nécessitent souvent un traitement à l'aide de naloxone. Bien qu'il soit recommandé de garder de tels patients sous observation pendant 4 à 24 heures après l'administration de naloxone, on a de plus en plus tendance à donner le congé plus tôt. Cette étude prospective observationnelle auprès de patients apparemment victimes d'une intoxication aux opiacés examine la sécurité des décisions de congé précoce et la justesse des prédictions des résultats par les médecins une heure après l'administration de naloxone. Méthodes : L'étude fut menée au St. Paul's Hospital, un centre universitaire urbain qui traite la majorité des utilisateurs de drogues par injection de Vancouver (C.-B.). Les patients subirent une

Department of Emergency Medicine, St. Paul's Hospital, Vancouver, BC, and the Centre for Health Evaluation and Outcome Sciences, University of British Columbia, Vancouver

Received: Jan. 21, 2000; final submission received: Apr. | 4, 2000; accepted: Apr. 17, 2000

This article has been peer reviewed. 
évaluation en règle une heure après avoir reçu de la naloxone pour une intoxication présumée aux opiacés. Le profil démographique, les antécédents médicaux et l'examen physique furent inscrits sur des formulaires de données spécifiques et les médecins notèrent leur niveau de confiance face à un congé précoce. Lors du suivi, on identifia les patients qui durent subir une intervention d'urgence ou qui furent victimes d'un événement indésirable prédéterminé dans les 24 heures suivant leur évaluation d'une heure.

Résultats : Parmi 573 patients, $48 \%$ reçurent leur congé après moins de 2 heures, $23 \%$ après 2 à 4 heures et $29 \%$ après $>4$ heures. Quatre-vingt-quatorze patients gardés à l'urgence ou hospitalisés durent recevoir des soins aigus, notamment de l'oxygène d'appoint pour hypoxémie (74), une nouvelle dose de naloxone (52), l'administration intraveineuse d'antibiotiques (14), une ventilation assistée (13), un bolus liquidien pour de l'hypotension (12), du charbon activé pour une intoxication associée menaçante pour la vie (6), des agents inotropes i.v. (2), des antiarythmiques pour une tachycardie prolongée $>130$ battements/minute (1), et l'administration de bicarbonate pour $\left[\mathrm{HCO}_{3}\right]$ artériel $<5$ ou $\mathrm{CO}_{2}$ veineux $<5$ (1). Les médecins prédirent des effets indésirables avec une sensibilité à $94 \%$ et une spécificité à $59 \%$. Aucun patient ayant reçu son congé de l'urgence ne fut victime d'un événement indésirable dans les 24 heures suivantes.

Conclusions : Les médecins d'urgence sont en mesure d'identifier cliniquement les patients chez qui il y a un risque de détérioration après la maîtrise d'une intoxication présumée aux opiacés à l'aide de naloxone. En général, l'observation prolongée ou l'hospitalisation ne sont pas nécessaires. Les congés précoces sélectifs accordés aux patients victimes d'une intoxication présumée aux opiacés est possible et semble sans danger. Une règle de prédiction clinique peut être utile pour l'identification des patients éligibles à un congé précoce.

Key words: naloxone, heroin, opioid overdose, outcome

\section{Introduction}

Patients with opioid overdose often receive naloxone during their prehospital or emergency department (ED) care. Because of concerns about delayed adult respiratory distress syndrome (ARDS) and recurrent opioid toxicity after naloxone metabolism, ${ }^{1}$ most authors recommend 6 to 24 hours of observation after reversal of opioid overdose. ${ }^{2-4}$ However, this is often impractical because of ED and hospital bed shortages and because many patients desire prompt discharge after receiving naloxone.

The standard practice in our ED, where we treat 40 to 50 patients with opioid overdose per month, is to observe such patients for at least 1 hour after their last naloxone dose, then discharge them if deterioration seems unlikely. This decision is based on clinical gestalt, but probably involves criteria such as mentation, respiratory and hemodynamic stability, and the ability to walk unaided. If it is true that experienced clinicians can accurately identify patients at risk of adverse events after naloxone reversal of opioid overdose, then it should be possible to develop a clinical decision rule for the safe early discharge of these patients. ${ }^{5,6}$

The objectives of this prospective observational study were to determine the rate of adverse events in patients given naloxone for presumed opioid overdose, to evaluate ED physicians' ability to risk stratify these patients, and to confirm the safety of selective early discharge.

\section{Methods}

\section{Setting and patients}

The study was conducted in the emergency department at St. Paul's Hospital, an inner city, 442-bed university-affiliated tertiary care facility in Vancouver, BC. St. Paul's ED has an annual census of 54,000 patients and cares for most of the city's injection drug users. All patients who received naloxone in the prehospital or ED setting because of suspected opioid overdose were eligible for the study. Vancouver's Emergency Medical Services (EMS) protocol for naloxone administration requires depressed mental status, respiratory rate $<10$ breaths/min, and evidence of drug use. Patients were excluded if they died in the ED within 1 hour of receiving naloxone, if they left the ED against medical advice, or if they refused to consent to follow-up. This study was approved by the University of British Columbia Ethics Committee on Human Experimentation.

\section{Data collection}

ED research assistants identified eligible patients, recorded demographics and notified attending physicians when 1 hour had elapsed after naloxone administration. Physicians documented the patient's initial response to naloxone, as determined using information from EMS and ED staff or by direct observation. Patients were asked to provide follow-up telephone or pager numbers, both their 
own and those of friends, relatives, hotel clerks or any other potential contacts. ED physicians recorded specific clinical data, including overdose drug and route, naloxone dose and route, past medical history, concurrent medications, alcohol and recreational drugs used within the preceding 24 hours and symptoms at the time of the ED exam. Physicians then performed a standardized physical exam, documenting vital signs, oxygen saturation, Glasgow Coma Scale, pupil responses, lateralizing neurologic signs, evidence of trauma, adventitious lung sounds and ability to ambulate. At this time (1 hour post-naloxone), physicians were asked to make a (sham) decision to "discharge now" or "observe." This decision reflected the physician's perception that the patient was "medically clear" and does not imply that discharge occurred immediately. In many cases, "discharge now" patients were held in the ED to address social, psychiatric or other issues. At the 1-hour assessment, physicians were also asked to rate their level of comfort with discharge on the following scale: very uncomfortable, somewhat uncomfortable, unsure, somewhat comfortable, and very comfortable.

\section{Outcomes}

Adverse events (AE) included death or the need for predefined hospital-based interventions within 24 hours of the 1-hour assessment (Table 1).

Table 1. Predefined adverse events and interventions within 24 hours of "safe discharge" assessment $(n=94)$ *

\begin{tabular}{|c|c|}
\hline Event & No. \\
\hline Supplemental oxygen for hypoxia (saturation $<92 \%$ ) & 74 \\
\hline $\begin{array}{l}\text { Repeat naloxone for respiratory rate }<10 \\
\text { breaths/min or oxygen saturation }<92 \%\end{array}$ & 52 \\
\hline $\begin{array}{l}\text { Intravenous (IV) antibiotics for suspected } \\
\text { pneumonia, sepsis, or central nervous system } \\
\text { infection }\end{array}$ & 14 \\
\hline Assisted ventilations & 13 \\
\hline $\begin{array}{l}\text { Fluid bolus }>1 \mathrm{~L} \text { for a systolic blood pressure } \\
<80 \mathrm{~mm} \mathrm{Hg}\end{array}$ & 12 \\
\hline $\begin{array}{l}\text { Administration of charcoal for suspected serious } \\
\text { co-ingestion }\end{array}$ & 6 \\
\hline IV inotropic agents & 2 \\
\hline $\begin{array}{l}\text { Antiarrhythmic medications for sustained } \\
\text { tachycardia }>130 \text { beats } / \text { min }\end{array}$ & 1 \\
\hline $\begin{array}{l}\text { Bicarbonate for } \mathrm{HCO}_{3}<5 \mathrm{mmol} / \mathrm{L} \text { in arterial blood, } \\
\text { or }\left[\mathrm{CO}_{2}\right]<5 \mathrm{mmol} / \mathrm{L} \mathrm{Hg} \text { in venous blood }\end{array}$ & 1 \\
\hline Death & 0 \\
\hline Dialysis & 0 \\
\hline Electrical cardioversion & 0 \\
\hline Non-elective surgical procedure & 0 \\
\hline Mannitol & 0 \\
\hline Total events & 175 \\
\hline
\end{tabular}

\section{Patient follow-up}

Follow-up was conducted by research staff who were blinded to clinical data and 1-hour discharge decisions. Patients who remained in the ED for further observation and treatment or were admitted from the ED had their charts reviewed for the duration of their hospital stay to determine the occurrence of adverse events. Patients who were discharged from the ED were given a contact card and asked to call the ED research office to provide follow-up. If they failed to do so, ED research staff attempted to phone them or reach them indirectly through the alternate contacts provided. Many patients who could not be contacted by phone were identified and interviewed during subsequent $\mathrm{ED}$ visits. When patients were contacted directly, nurses recorded specific outcome data on study follow-up forms. When only indirect follow-up was available (through relatives or acquaintances), the "contact" was often able to provide only limited information; therefore, in all cases of indirect contact, subsequent database searches were performed to assure that these patients did not require hospital care within the study time frame. After several months, we compiled a list of all patients who had not been directly contacted and searched the medical records databases of 6 local hospitals where these patients could have subsequently presented for care. For those who had a repeat hospital visit within 24 hours of the safe discharge assessment, we determined the reason for the visit and documented any treatment provided. Finally, we searched the records of the Chief Coroner's Office and the Department of Vital Statistics to determine whether any patients had died after ED discharge.

\section{Statistics}

In a subset of 96 patients, inter-observer reliability for the safe discharge decision was determined by having a second ED physician examine the patient and complete an interobserver data form. Kappa values for agreement beyond chance were calculated. Descriptive statistics, including medians, means and standard deviations, were calculated for continuous variables. Frequency and percent were reported for categorical variables. The ED physician's decision to discharge (at 1 hour) or hold for observation was analyzed as a diagnostic test for the prediction of adverse events. Sensitivity, specificity, and predictive values with exact $95 \%$ confidence intervals were calculated.

\section{Results}

\section{Patients}

From May 1997 to May 1998, 578 patients were enrolled in the study. Five patients who received additional naloxone within 24 hours of their safe discharge assessment were 
excluded from analysis. Four of these admitted to re-injecting heroin after ED discharge and 1 required reversal of fentanyl sedation for a Colles' fracture reduction 2 hours after the "index" naloxone administration. Table 2 summarizes demographic and naloxone administration data. Mean age in the study sample was 35.7 years, and $82 \%$ of patients were male. Prior to naloxone administration, mean respiratory rate was 5.1 and Glasgow coma score was 5.7. Overall, 93\% admitted to index opioid abuse - in most cases, heroin. Figure 1 summarizes patient follow-up and shows that no deaths occurred within 24 hours of the early discharge assessment.

\section{Adverse events}

Table 1 shows that although no patients died within 24 hours, 94 (16.4\%) required 175 hospital-based interventions after the safe discharge assessment - most often for supplemental oxygen for hypoxia $\left(\mathrm{O}_{2}\right.$ saturation $\left.<92 \%\right)$ or for repeat naloxone for bradypnea.

\section{Disposition}

At the 1-hour assessment, ED physicians indicated that 282 patients were safe for discharge and that 285 required further observation. A disposition decision was not recorded for 6 patients. The kappa value for inter-observer agreement on disposition decision ("discharge now" vs. "observe") was 0.67 in 96 paired determinations. Table 3, which corre-

\begin{tabular}{|c|c|c|}
\hline Demographic/naloxone features & No. (a & d \%) \\
\hline Age $^{*}$ & 35.7 & $(10.5)$ \\
\hline Male sex & 472 & $(82.4)$ \\
\hline $\begin{array}{l}\text { Respiratory rate before naloxone, * } \\
\text { breaths/min }\end{array}$ & 5.1 & (5.7) \\
\hline Glasgow coma score before naloxone* & 5.7 & $(4.0)$ \\
\hline Admitted to index opioid abuse & 531 & $(92.7)$ \\
\hline Opioid alone & 387 & $(67.5)$ \\
\hline Opioid plus other drug & 144 & $(25.1)$ \\
\hline Admitted index heroin use & 492 & $(85.9)$ \\
\hline Denied index opioid use & 38 & $(6.6)$ \\
\hline No data on index opioid use & 4 & $(0.7)$ \\
\hline Received prehospital naloxone & 513 & $(89.5)$ \\
\hline Received ED naloxone & 132 & $(23.0)$ \\
\hline Prehospital and ED naloxone & 74 & (12.9) \\
\hline SC naloxone & 504 & $(88.0)$ \\
\hline IV naloxone & 133 & $(23.2)$ \\
\hline SC and IV naloxone & 74 & (12.9) \\
\hline $1 / 2$ / 3 / >3 naloxone doses, $+\%$ & \multicolumn{2}{|c|}{75 / 17 / 6 / 2} \\
\hline
\end{tabular}

SC = subcutaneous; IV = intravenous

* Mean (and standard deviation [SD])

tThe mean total dose of naloxone was $0.93 \mathrm{mg}(\mathrm{SD}, 0.47)$ lates disposition decision with patient outcome, shows that 6 of 282 "discharge now" patients and 88 of 285 "observe" patients suffered an adverse event after the 1-hour discharge assessment. Based on these data, physician sensitivity, specificity, positive predictive value and negative predictive value were $93.6 \%$ (95\% CI, 86.6\%-97.6\%), 58.4\% (95\% CI, 53.8\%-62.8\%), 30.9\% (95\% CI, 25.6\%-36.6\%) and $97.9 \%$ (95\% CI, 95.4\%-99.2\%) respectively. Of the 6 "discharge now" patients who suffered adverse events, all required supplemental $\mathrm{O}_{2}$ and 2 required repeat naloxone. These events occurred before the patients left the ED; therefore, no patient who experienced an adverse event was actually released from the ED.

Ultimately, 26 patients (4.5\%) were admitted to hospital and 547 (95.5\%) were discharged from the ED. Indications for hospitalization in 26 patients were pneumonia $(n=9)$, suicidal ideation $(n=7)$, prolonged overdose symptoms $(n=3)$, possible ARDS $(n=2)$, urinary tract infection $(n=$

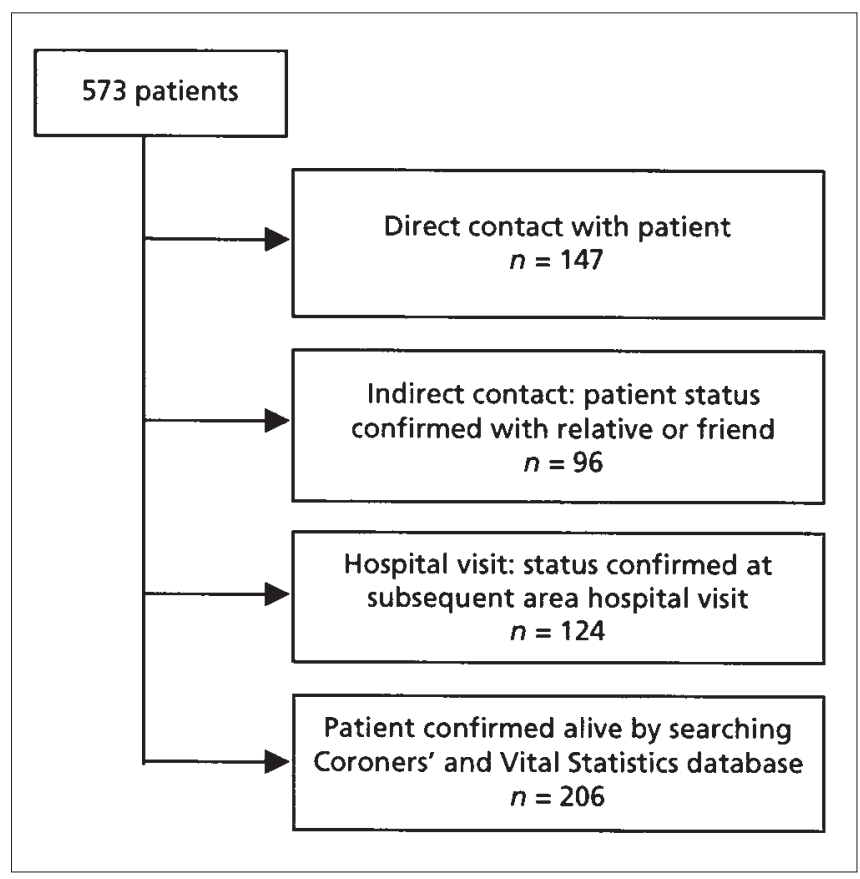

Fig. 1. Follow-up

Table 3. Emergency physician (EP) discharge decisions and patient outcomes

\begin{tabular}{lccc} 
EP decision & $\begin{array}{c}\text { Adverse } \\
\text { outcome }\end{array}$ & $\begin{array}{c}\text { No adverse } \\
\text { outcome }\end{array}$ & Total \\
\hline Observe & 88 & 197 & 285 \\
Discharge & 6 & 276 & 282 \\
Total & 94 & 473 & 567 \\
\hline
\end{tabular}

Sensitivity $=93.6 \% ; 95 \%$ confidence interval $(\mathrm{CI}), 86.6 \%-97.6 \%$. Specificity $=$ $58.4 \%$; $95 \% \mathrm{Cl}, 53.8 \%-62.8 \%$. (+) Predictive value $=30.9 \% ; 95 \% \mathrm{Cl}, 25.6 \%-$ $36.6 \%$. (-) Predictive value $=97.9 \% ; 95 \% \mathrm{Cl}, 95.4 \%-99.2 \%$. 
2), stab wounds ( $n=1)$, rhabdomyolysis/acute renal failure $(n=1)$ and cerebral anoxia/ARDS (death) $(n=1)$. Overall, median hospital length of stay was 2.1 hours, with 278 patients (48.5\%) staying less than 2 hours, 130 staying $2-4$ hours and 165 (28.8\%) staying more than 4 hours.

In the admitted group there were 3 cases of possible ARDS, but only one was confirmed radiologically. This patient presented to the ED postcardiac arrest with a Glasgow coma score of 3, and died more than 24 hours after hospital admission. The second patient was post-CPR with a radiological diagnosis suggestive of pulmonary contusion, although ARDS could not be ruled out. This patient left hospital 25 hours after the 1-hour assessment. The third patient had a radiological diagnosis of probable pneumonia, but ARDS could not be excluded. This patient left hospital 46 hours after the 1-hour assessment. Neither of these patients required endotracheal intubation, and both left hospital against medical advice.

Figure 2 shows that clinical risk stratification is possible and that physicians were able to predict the likelihood of adverse events. In the group of 227 patients that physicians felt "very comfortable" discharging, only 8 (3.5\%) experienced an adverse event, while in the group of 153 that physicians felt "very uncomfortable" discharging, 56 (37\%) suffered an adverse event.

\section{Discussion}

Our study suggests that serious adverse events are uncommon after naloxone reversal of suspected opioid overdose, that high risk patients can be identified on clinical grounds, that selected patients may be discharged as early as 1 hour

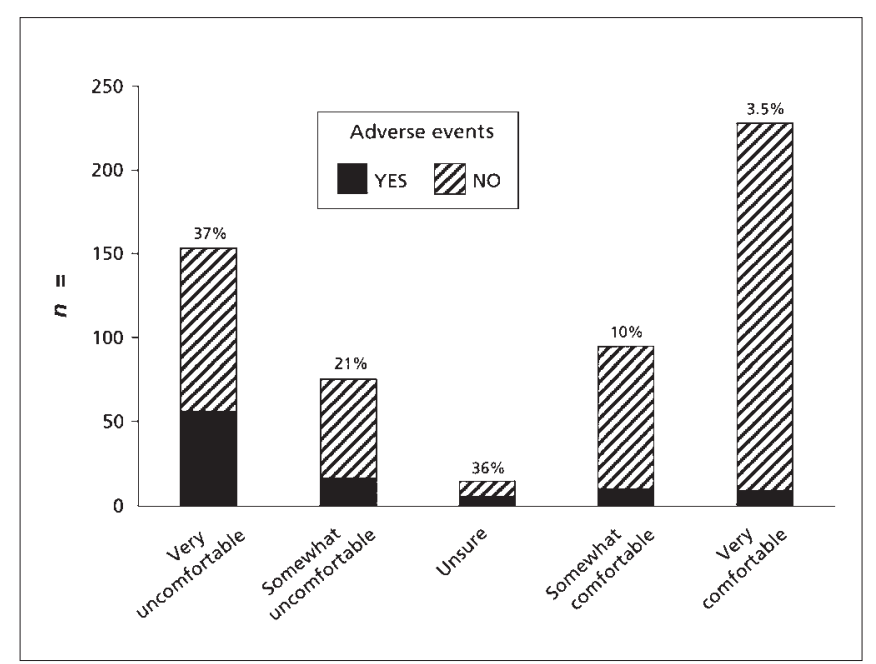

Fig. 2. Emergency physician comfort with early discharge vs. patient outcome. Percentages denote the proportion of patients per group experiencing adverse events. after opioid reversal, and that prolonged observation is usually unnecessary. In this study, the median length of stay was 2.1 hours after naloxone administration - substantially shorter than the recommended 6 to 24 hours. At 1 hour, emergency physicians identified 88 of 94 patients who subsequently required a hospital-based intervention. More importantly, no patients who were discharged from the ED subsequently suffered a serious adverse outcome.

We found only 2 previous studies that addressed recurrent toxicity and the need for prolonged observation after naloxone administration. One of these studies ${ }^{7}$ concluded that hospital admission is unlikely to benefit patients who lack pulmonary findings in the ED; however, these conclusions were based on a retrospective review of hospital charts and EMS transport records. The other study ${ }^{1}$ was a retrospective audit dealing largely with oral opioid toxicity. Despite some limitations in the current study, we believe it provides the most valid data available with respect to safe disposition after opioid overdose.

Opioids produce analgesic effects, respiratory depression, delayed gastrointestinal motility, miosis, euphoria and physical dependence. ${ }^{8}$ Respiratory depression, the primary cause of death in opioid overdose, is due to direct inhibition of the brainstem respiratory centre and decreased responsiveness to carbon dioxide. ${ }^{9}$ Route of administration is important, and most significant overdoses and fatalities occur when opioids are taken intravenously. ${ }^{9}$ Heroin is particularly toxic because of high lipid solubility, which allows it to cross the blood-brain barrier within seconds and achieve high brain levels. ${ }^{10}$

Naloxone is also lipid soluble and enters the brain rapidly. Reversal of respiratory depression is evident 3-4 minutes after IV and 5-6 minutes after subcutaneous administration. ${ }^{11}$ The reported half-life of naloxone is 1.1 hours, ${ }^{10}$ but the activity of a 0.4-mg IV dose appears to be clinically negligible by 45 minutes. ${ }^{2}$ Existing literature recommends IV boluses of $0.1-2.0 \mathrm{mg}$, repeated every 3 minutes as needed, to a maximum dose of $10 \mathrm{mg} .^{12}$

Smaller doses, careful titration or continuous infusion may be used to reverse respiratory depression while avoiding the often violent reaction to acute opioid reversal. ${ }^{13}$

Parenteral and commonly used oral opioids, including morphine, hydromorphone, codeine, hydrocodone and oxycodone, have an action duration of 4 to 6 hours, substantially longer than naloxone's 45 minutes $;{ }^{10}$ therefore, respiratory depression may recur after successful treatment. Another concern is delayed ARDS, which has been reported in the setting of opioid overdose. ${ }^{14-16}$ Because of these concerns, a period of observation is necessary after naloxone therapy, but the duration of observation is controversial 
and current recommendations range from 4 to 48 hours..$^{2-4,7}$

Unfortunately, it is often difficult to adhere to these recommendations. ED stretchers are in short supply - they are usually $100 \%$ occupied. In addition, this patient group is frequently not amenable to prolonged ED observation after receiving naloxone; holding them may involve forcible restraint. Moreover, for several reasons the authors believe that prolonged observation is generally unnecessary. Respiratory arrest after intravenous opioid use typically occurs immediately after drug injection and before redistribution. Parenteral heroin has a 4-5 hour action duration, but its distribution half-life is only 30 minutes. ${ }^{10}$ It seems likely, therefore, that, 1 hour after naloxone administration, heroin levels will have dropped and brain levels will be falling to the extent that recurrent life-threatening respiratory depression will not occur. In addition, at 1 hour the effects of naloxone are clinically negligible ${ }^{2}$ and any depressant effects of longer-acting opioids should be clinically apparent. With respect to ARDS, 2 studies suggest that ARDS secondary to opioid overdose is an infrequent complication that is usually clinically evident soon after resuscitation. ${ }^{15,17}$ For all of these reasons we developed our standard practice of early discharge.

In this study, one patient died after the 24-hour follow-up period, many required critical interventions (Table 1) and others developed major complications; however, all of the patients who suffered major complications were identified on clinical grounds at the 1-hour assessment and none were actually discharged from the ED. It is of concern that 6 of the 282 patients deemed "safe to discharge" at 1 hour suffered an adverse event; however, it is not clear that these 6 events (oxygen desaturation $<92 \%$ or respiratory rate $<10$ breaths/min) would have caused morbidity had they been untreated. Our data illustrate a problem inherent in studying "sham" clinical decisions. Although the 6 patients were deemed "safe for discharge," none were actually discharged from the department, suggesting that real clinical decisions may be more sensitive than the sham decisions reported.

\section{Study limitations}

The primary shortfall of this study relates to follow-up, and it is correct to say that our follow-up was not sufficient to detect all adverse events. Many of our patients had no phone or fixed address, and follow-up was often difficult. It is likely that minor adverse events that did not require hospital treatment occurred and were not documented. It is extremely unlikely, however, that unrecognized mortality occurred because the government's Vital Statistics database captures all deaths in the region and it is unrealistic to think that a study subject could leave the region within the time it would take for re-sedation to occur. Further, because we searched the health records databases of hospitals within 50 $\mathrm{km}$ of downtown Vancouver, it is unlikely that study patients underwent other hospital-based treatment without our knowledge. It is conceivable, though, that study patients could have sought follow-up care under assumed names or perhaps travelled to distant hospitals for treatment of delayed adverse events.

Some readers might think it peculiar that we defined an adverse event not by the event itself but by the treatment of the event. For example, within the study, "respiratory rate $<10$ breaths/min" was not an AE, while "naloxone administration for respiratory rate $<10$ breaths/min" was. We chose this approach for important reasons. First, it allows the incorporation of clinical judgement. To illustrate, many people have respiratory rates $<10$ breaths/min during sleep. When such a finding was noted, but the attending physician determined that it required no intervention, we felt it should not be considered an adverse event. Second, it was our objective to study the safety of early discharge or, conversely, the need for prolonged observation. We believed that if an event occurred (e.g., respiratory rate $<10$ breaths/min) but required no treatment, it would not indicate a need for hospital observation, nor would it preclude safe discharge.

Some might criticize the fact that we diagnosed opioid overdose on clinical grounds and did not perform toxicology screening. But this reflects real life: opioid toxicity is a clinical diagnosis that rarely if ever requires lab confirmation. Another possible shortfall of this study is that we excluded patients who discharged themselves against medical advice before the 1-hour assessment, and these patients may be a high-risk group. Whether patients can be considered mentally competent to refuse care after opioid overdose is a concern to some; however, it is our experience that after naloxone has eliminated opioid effects it often becomes difficult to declare these people mentally incompetent.

External validity is also a concern. Due to familiarity with injection drug users, our hospital's emergency physicians have developed skill in assessing heroin overdose victims. The results of this study, and the success of our physicians in recognizing high-risk patients, may not be transferable to all settings. The fact that heroin purity varies from city to city and month to month may also limit the generalizability of our results.

Our next goal is to investigate objective and reliable clinical parameters that can be used to identify patients at low risk of having adverse events or requiring critical hospitalbased interventions. These predictors can be incorporated into a clinical prediction rule that could be used by less 
experienced clinicians to assess the safety of early discharge after naloxone administration. In today's environment of diminishing health resources, it is important to maximize ED efficiency while maintaining safety. The financial, logistical and human-resource costs of observing patients longer than necessary are too high.

\section{Conclusions}

Serious adverse events are relatively uncommon after naloxone administration for presumed opioid overdose. High-risk patients can be identified on clinical grounds early after naloxone administration. Selective early discharge is safe, and prolonged ED observation is usually unnecessary. A clinical decision rule for early discharge of patients with presumed opioid overdose should be developed.

Acknowledgements: This study was funded by the British Columbia Health Research Foundation. In addition, the authors wish to thank the nurses and emergency physicians of St. Paul's Hospital Emergency Department, without whose efforts and perseverance this study would not have been possible.

\section{References}

1. Watson WA, Steele MT, Muelleman RL, Rush MD. Opioid toxicity recurrence after an initial response to naloxone. J Toxicol Clin Toxicol 1998;36:11-7.

2. Allen T. Narcotics. In: Rosen P, Barkin R, editors. Emergency medicine: concepts and clinical practice. St. Louis: Mosby-Year Book Inc; 1998. p. 2603-16.

3. Howland MA. Antidotes in depth. In: Goldfrank L, Flomenbaum N, Lewin N, Weisman R, Howland M, Hoffman R, editors. Goldfrank's toxicologic emergencies. Stamford: Appleton and Lange; 1998. p. 998-1009.

4. Opioids. In: Ellenhorn MJ, et al, editors. Ellenhorn's medical toxicology: diagnosis and treatment of human poisoning. 2nd ed. Baltimore: Williams and Wilkins; 1997. p. 430-46.

5. Wasson J, Sox H, Neff R, Goldman L. Clinical prediction rules: applications and methodological standards. N Engl J Med 1985; 313:793-9.

6. Laupacis A, Sekar N, Stiell I. Clinical prediction rules: a review and suggested modifications of methodological standards. JAMA 1997;277:488-94.

7. Smith D, Leake L, Loflin J, Yealy D. Is admission after heroin overdose really necessary? Ann Emerg Med 1992;21:1326-30.

8. Schwartz M. Opiates and narcotics. In: Haddad LM, Shannon MW, Winchester JF, editors. Clinical management of poisoning and drug overdose. 3rd ed. Philadelphia: WB Saunders; 1998. p. 505-22.

9. Sporer K. Acute heroin overdose. Ann Intern Med 1999; 130:584-90.

10. Reisine T, Pasternak G. Opioid analgesics and antagonists. In: Hardman JG, Limbird LE, Molinoff PB, Ruddon RW, Gilman A, editors. Goodman \& Gilman's the pharmacological basis of therapeutics. 9th ed. New York: McGraw-Hill; 1996. p. 521-55.

11. Wanger K, Brough L, Macmillan I, Goulding J, MacPhail I, Christenson J. Intravenous vs subcutaneous naloxone for out-ofhospital management of presumed opioid overdose. Acad Emerg Med 1998;5:293-9.

12. Doyon S. Opioids. In: Tintanelli J, Kelen G, Stapczynski JS, editors. Emergency medicine: a comprehensive study guide. 5th ed. New York: McGraw Hill; 2000. p. 1109-12.

13. Goldfrank L, Weisman R, Keith J, Errick JK, Lo MW. A dosing nomogram for continuous infusion intravenous naloxone. Ann Emerg Med 1986;15:566-70.

14. Dauberstein JL, Kaufman DM. A clinical study of an epidemic of heroin intoxication and heroin induced pulmonary edema. Am J Med 1971;51:704-14.

15. Osterwalder J. Patients intoxicated with heroin or heroin mixtures: How long should they be monitored? European J Emerg Med 1995;2:97-101.

16. Larpin R, Vincent A, Perret C. Hospital morbidity and mortality of acute opiate intoxication. Presse Medicale 1990;19:1403-6.

17. Sporer K, Firestone J, Isaacs S. Out-of-hospital treatment of opioid overdoses in an urban setting. Acad Emerg Med 1996;3:660-7.

Correspondence to: Dr. Jeremy Etherington, Department of Emergency Medicine, St. Paul's Hospital, 1081 Burrard St., Vancouver BC V6Z 1Y6; 604 682-2344 x65480; ethering@interchange.ubc.ca 